\title{
Discursive Interventions
}

\author{
On the Relationship between the Aesthetic and the Political \\ in Late Modernity
}

\section{Henrik Kaare Nielsen}

The article addresses the aesthetic and the political as modern modes of practice that are discursively separated, but nevertheless continuously involved in a conflictual interplay with one another. The article discusses the nature of the limits between the aesthetic and the political, and makes the argument that the interplay between the two modes of practice occurs in the shape of a variety of different forms of mutual intervention and that these forms of intervention represent qualitatively different perspectives for the further development of modern culture and society.

\section{The differentiation and conflictual interplay of discourses}

An understanding of the contemporary development of the relations between aesthetic and political practice can advantageously be based on a main feature of the process of modernisation: that social practice has differentiated itself into a number of specific types of discourses and related fields of action of a more or less institutionalised nature (Habermas 1981). Science is an example of a strongly institutionalised field of practice which derives its legitimacy and its criteria of validity and relevance from a specific type of discourse and which solely answers to the cognitive rationality of action and the related, uncompromising and, in principle, open-ended search for truth.

The field of political practice comprises both formally and informally institutionalised forums and types of agents (from the parliaments and political parties to grassroots initiatives and individual actors), and these all operate according to the basic rationale of the field: the struggle for power in respect to the allocation of societal resources in the broadest sense and thereby to the social distribution of life opportunities. Within the normative framework of the moral-practical rationality of action and democratic political culture, political discourse is about conquering the definition power over society's common concerns, and, as part of this pro- 
cess, about the contending political agents' struggle to close and determine the social formation of meaning on their own premises. The discourse is, in other words, to a high degree intrinsically goal orientated.

The field of aesthetic practice is of a correspondingly composite nature: it comprises both the highly institutionalised expert culture of art, the heterogeneous field of popular culture, and late modernity's overall process of aestheticization which tends to equip the whole life-world of modern individuals with experiential appeals to senses and emotions (Welsch 1990; Seel 2003; Nielsen 1996). Contrary to the orientation of political discourse towards determining definite, universal and goal-orientated principles for the development of society, aesthetic discourse is however characterised by its non-directed nature. The purpose of aesthetic practice is the practice itself, and when it unfolds on its own premises, it challenges established formations of meaning, but without prescribing edifying alternatives. Aesthetic discourse, in other words, opens the social formation of meaning in an undetermined way, thereby encouraging the agents of aesthetic practice to perform the unceasing, autonomous, and pleasure-motivated seeking process between a specific phenomenon and a non-existing overall concept which characterises the process of aesthetic experience (Bubner 1989; Kant 1790/1963). In other words, whereas political discourse in a Kantian sense operates according to the determinative judgement, aesthetic discourse works in the mode of the reflective judgement. Furthermore, aesthetic discourse is capable of activating intellectual as well as emotional and sensory forms of experience and thus represents a more nuanced and wide-ranging potential for Bildung ${ }^{1}$ than a purely cognitive or moral discourse could accomplish.

The distinction between these fields of practice and types of discourse has been a crucial foundation for the development of both the institutions and the everyday life practice of modernity. But it is important to be aware that this fundamental and thorough process of differentiation does not imply that the fields of action and the discourses remain unaffected by one another. They are currently involved in a complex, mutual interplay in which they engage in more or less conflictual relations with one another, and in which genuine issues of hegemony may occasionally arise. This conflictual interplay forms a basic condition of the social practice of modernity, and if it takes place in ways that allow the maintenance of the respective discursive domains, it may productively stimulate the fields of practice involved. But if the balance is disturbed, and one form of discourse marginalises the other, problematic and dedifferentiating consequences may arise that make society as a whole poorer in terms of the 
variety of types of knowledge and reflection and thus reduce its ability to make qualitative distinctions and reflect nuanced, alternative possibilities of development.

In this sense, the field of scientific practice is currently involved in a hegemonic struggle in which the political and economic fields of practice are attempting to install their own goal-orientated utilitarian discourses in the field of scientific practice as well through legislation, resource incitements, and public pressure. As mentioned, the crucial question is not whether this kind of intervention exists - it currently does - but whether it takes shapes in which the discourse of science still has enough scope to unfold on the premises of the uncompromising search for truth, or whether the external pressure for immediately applicable research results is getting so strong that scientific discourse will no longer be able to create meaning on its own terms and will therefore break down and be replaced by a mercantile discourse.

Taking this line of reasoning, in the following I will take a closer look at the relation between the aesthetic and the political in late modernity, first, through a brief characterisation of political intervention into the field of aesthetic practice and thereafter through a discussion of three different types of aesthetic intervention into the field of political practice.

\section{Types of intervention between the political and the aesthetic}

In Denmark and related countries, public cultural policy represents the most manifest intervention by the field of political practice into the aesthetic field of practice. Here, aesthetic practice is framed by legislation, the selective allocation of resources, and administrative procedures which privilege the parts of aesthetic practice contemporarily recognised as socially valuable - and neglect the rest of the field. This selective allocation of funding is rooted in an enlightenment- and welfare-orientated sociopolitical objective of cultural policy - or, in other words: selected parts of aesthetic practice are assumed to represent positive potentials for the Bildung and empowerment of the citizens and thus for the ongoing process of societal democratisation (Duelund 1995; Langsted 1990; Nielsen 2001).

But as should be noticed, in the Danish tradition of cultural policy this objective of political intervention into aesthetic practice is assumed to be realised through aesthetic practice itself: when aesthetic activities and processes of experience have the opportunity to unfold on their own terms, Bildung and democratic potentials emerge as 'spin-off'. In other words, this concept of cultural policy aims at establishing an interplay be- 
tween political and aesthetic practice which does not affect their respective discursive autonomy. Admittedly, in later years, attempts have been made to marginalise this tradition of cultural policy in order to orientate cultural life more strongly towards the market and thus subordinate it to mercantile discourse. But so far this turn has not been able to create political consensus, and its foremost spokesman, the Minister of Culture, Brian Mikkelsen, also occasionally - e.g. in the initiative of the national canon- explicitly refers to the Bildung-orientated socio-political objective, so it would be too hasty to speak of a hegemonic rupture with traditional cultural policy.

A further dimension of the interplay between the political and the aesthetic discourse established by cultural policy is the political power play triggered off in cultural life by the efforts of the individual institutions and agents to present themselves as worthy of funding, but these political struggles are focused on the economic conditions of aesthetic practice and do not necessarily affect its discursive autonomy.

Conversely, in the following the focus will be on the interventions of aesthetic discourse into the political sphere of practice, including the ways in which aesthetic discourse is being integrated into the political process on the discursive premises of the latter. For this purpose, I shall introduce a model I have presented earlier in greater detail and which concerns the basic relations of the political process of modern, democratic societies: ${ }^{2}$

A: (social and cultural conflicts $\leftrightarrow$ power relations) $\rightarrow$ compromise

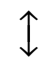

B: collective historical experience $\rightarrow$ consensual ethics/political culture

The model conceptualises the political process as an integrated interplay between two levels. On the one hand, a level of conflict (A), characterised by non-violent struggles of interests being settled in the form of always temporary compromises, and mediated by the current relationship of power between the contending parties. On the other hand, a level of consensus (B) which processes and condenses the ongoing, collective formation of experiences of conflict from level A to a consensual, ethical framework. This framework is not up for discussion in the concrete political disputes, but serves as the evident, common standard of social interaction to which the ongoing struggles of interests and the formation of compromises must at any time be able to legitimise themselves. In other words, this experience-based, "tacit" ethical consensus functions as a civilising, 
normative sounding-board under society's handling of conflicts and thus constitutes the core of the democratic political culture which is currently being created, recreated and transformed as part of the broader societal formation of experience. The developmental rhythm of this consensus, though, is slower than that of the conflicts and the formation of compromises on level A. Furthermore, political culture will always represent a hegemonic interpretation of the societal experiences of conflict, and tends to play down or even marginalise social interests and needs that have not been able to manifest themselves in a sufficient position of power in order to gain influence in the formation of compromises.

In this sense, a prominent principle of aesthetic intervention into the political process consists in the use of aesthetic effects by political agents to establish themselves in a position of strength in the struggle of interests and the formation of compromises on level A. The articulation of interests and the positioning in the political power-play always imply an aesthetic/performative dimension (e.g. in the shape of rhetorical style, visual staging, etc.) (Schulze 2006), and occasionally this dimension in interplay with political and economic factors may be decisive for the balances of power in the political struggle. As regards the fundamental relationship between the aesthetic and the political, however, the crucial question appears to be on which premises and with which type of appeal the relationship is established: Is it a dialogic, challenging appeal which allows the process of aesthetic experience to unfold? Or, on the contrary, a monologic, tranquilising approach that only appeals to regressive fascination?

In other words, aesthetic intervention into the political sphere of practice can mean a variety of things and imply correspondingly different perspectives for the development of culture and society. In the following, a distinction will be made between tendencies towards a depoliticising aestheticization of politics, a polarising aestheticization of politics, and artistic interventions into the field of political practice.

\section{Depoliticising aestheticization of politics}

A significant dimension of the relationship between the aesthetic and the political in late modernity is constituted by an overall tendency towards aestheticization which is characterised by the dispersion of the appeal to the sensory and emotional qualities of experience to all relations in society, and which implies transcending discursive and institutional borderlines (Knodt 1994; Ziehe 2004; Nielsen 2005; Bisgaard \& Friberg 2006). The fact that this type of aestheticization has achieved an almost 
hegemonic status is due to its ability to channel a heterogeneous multiplicity of dynamics that are active in the current development of culture and society. This includes not least the dynamics of culturalisation which originates in the process of individualisation and the destabilisation of traditional forms of life and identity. Furthermore, aestheticization draws on the dynamics which is created by the fact that attention today is a scarce resource, over which an ongoing struggle takes place between a multiplicity of agents: individuals striving for self-reassurance and social identity, politicians up for election, the branding strategists of private and public organisations, the media and the advertising business - all of them are making onslaughts on established borderlines by means of intensified sensory and emotional appeals in order to compel attention and thereby - assumedly - recognition, wealth, and power.

This effect-straining type of aestheticization, which unfolds with particular intensity in the electronic media, tends to intertwine with a monologic market discourse that in reality merely aims at pleasing and confirming the recipients in their private wishful fantasies and inclinations. In other words, this is a reduced version of aesthetic discourse which marginalises the potential of the discourse for challenging established worldviews and self-conceptions and creating an interplay between senses, emotions and intellect. Critical, investigating reflection and the dialogical perspective in relation to common concerns of society are not addressed by this restricted version of aesthetic discourse, which instead encourages one-dimensional lingering on immediate sensations, emotions and moods (Prokop 2005).

Today, this general tendency towards aestheticization represents a prominent condition of competition in public space, and it thereby also determines the premises on which the agents of political life operate. Furthermore, in the course of globalisation and the general rise in complexity, it is becoming increasingly difficult to establish a clear understanding of societal relations from the perspective of everyday life. As a result of this development, it becomes a central task of the political system to secure the continuing trust of the population towards the institutions of society, but because of the complex and non-transparent nature of institutions and globalised societal relations, it is not possible to establish this trust solely in the media of a political or a cognitive discourse (Giddens 1991). Elucidating measures are required, and in this respect an aesthetic reduction of complexity presents itself as an immediately effective way of creating trust: the sympathetically staged power figure as such incarnates the guarantee that things are probably in order concerning non-lucid matters like the economy, pensions, food control, security, and so forth. 
In addition, by way of the institutionalisation of the welfare state as generally accepted, overall compromise on the level of the nation-state, and the extensive world-market-strategic technocratisation of the framework of the political process, which the privileged OECD countries are propelling forward in unanimity, it has increasingly become difficult to distinguish substantial differences between the positions of the various political parties. The technocratic agenda unites the whole political mainstream under the motto "There is no alternative", and it has therefore become nearly impossible for the leading political parties to profile themselves in terms of political content.

Under these circumstances, political positioning and power struggles are increasingly carried out with aesthetic means: the performance of the individual politician, his/her ability to communicate enthusiasm, attract sympathy, demonstrate quick wit, rhetorically make problems disappear, look good on TV, and so on, replaces political content in the struggle over political power. The trust in the institutions of society which is established in this way, however, must be characterised as uninformed trust, and the use that is being made of aesthetic discourse reduces it to the affirmative processing of senses and emotions, whereas the element of challenge and critical reflection is marginalised.

As mentioned earlier, the positioning in the political struggle always contains an aesthetic element, but since performativity tends to totally replace political content in the current situation, we are dealing with a process of dedifferentiation which could undermine public debate and democratic political culture. A political process which does not critically reflect a variety of alternative developmental possibilities and offer these for public dialogue, but conversely claims that nothing can be changed, denies actual problems, conflicts, and ambivalences in society. Instead, society is being staged as a set of harmonious contractual relationships, the solidity and credibility of which are being conjured up in the shape of the monologic, emotion-orientated marketing of the individual politician as a trustworthy person (smiling, well dressed, authoritative - and therefore 'trustworthy'), which characterises this type of aestheticization of politics. This development transforms the participating citizen into a passive consumer of pleasing, aestheticized appeals, depoliticises the political process, and weakens the collective formation of political experience - and thereby the capacity of the political process to tolerate differences and cope dialogically with conflicts when they manifest themselves from time to time in spite of the smoothened surface of public space. In other words, the ability of the political process to create meaning on its own conditions is threatened. 


\section{Polarising aestheticization of politics}

This overall diagnosis of tendencies towards conflict-denying, depoliticising aestheticization of politics in late modernity appears at first glance to be contradicted by the strong polarisation which, emanating from the fields of foreign policy and security policy, has left its mark on the political public sphere on both a national and an international level since the terrorist attack on the United States on September 112001 . This polarisation has a solid core of power politics concerning both geo-political and economic interests, including the question of controlling the 'terms of trade' in the Middle East and not least the access to the oil wells of the region. The constellation of interests surrounding these questions of power politics is of a highly complex nature in both the Middle East and in the West, but ever since September 2001 the multiplicity of interests and political positions in the field has been forced into a reductionist, dichotomous scenario.

This simplified picture furthermore corresponds with the fact that, in safeguarding their interests, both sides legitimise their bloodshed by claiming to be defending sublime values. In this way, the political conflict is being discursively transformed into a pure conflict of cultures, where, for instance, Samuel Huntington's thesis on the "Clash of Civilizations" (Huntington 1998) serves as a convenient legitimising ideology for the reductionism; and on this background, the polarisation develops a dynamics of its own in the public consciousness by way of a stylising, aesthetic discourse. We are, in other words, dealing with an aesthetic intensification of a political conflict, and from the start we are operating in a scenario where a political process based on reason, dialogue, and compromise-orientated interaction has no scope whatsoever.

The al-Qaeda terrorists perform their self-appointed role as safeguards of Middle Eastern interests against the "infidel" Western interference in the shape of an uncompromising, violence-based monologue of power. As is the case with all terrorism, this practice is rooted in a condition of political and military powerlessness which terrorists seek to transform into a position of strength and power by incalculably spreading death and mutilation among innocent civilians and thus creating a climate of horror in order to undermine the social and political stability of society.

In other words, the destruction of the basic conditions of democracy is a central element in the strategy of terrorism in general, but the current Islamic terrorism adds a calculated aesthetic dimension: the attacks are carried out as spectacular, orchestrated acts of violence. The horrifying experience of the collapse of the Twin Towers disrupted the established 
patterns of imagination as to what a destructive, misanthropic will is able to accomplish. Accompanied by the many hours of indeterminacy that ensued, during which time the international public had no idea as to who was responsible and what was the background, this act paved the way for a general aesthetic experience of sublimity in the Kantian sense of the word, i.e. a horror-stricken fascination in the encounter with an unknown, incalculable, and dangerous superior force.

This represents an extremely efficient type of aestheticization of politics which charges the political process with a conflictual but undetermined emotional intensity able to suspend the reason-based judgement of public debate and ultimately to cause the dissolution of democratic political culture from within. In full accordance with the intentions of its strategists, this process of aestheticization serves to strengthen their position in the political power play, but at the same time undermines the political process in its capacity for handling conflicts of interest in a civilised manner, and the perspective of this type of aestheticization of politics is therefore the replacement of politics by barbarism and the rule of violence.

The Western counterpart in this dichotomous scenario conducts a parallel aestheticization of politics: in a semi-religious setting, a complex, global constellation is stylised to the conflict between Good and Evil, between democracy and "the axis of evil", between freedom and terrorism. As a simple reflex of the fundamentalist worldview of the terrorists, the Western leaders form a political space of meaning which is modelled in accordance with the stereotypes of B movies: "Either you are with us or you are with the terrorists." The scenario is a permanent state of emergency with apocalypse lurking around the corner, and, consequently, with no scope for discussion and disagreement on the inner lines. We are, in other words, dealing with a highly reduced version of aesthetic discourse, since in this context it is being utilised to decomplexify and close down the public space of reflection.

This aesthetic reduction of complexity and the related positioning of the state leaders as firm, energetic, and uncompromising guarantors of democracy and peace against attacks from the powers of darkness strengthens them in the power struggles on the national level, and grants them an extended freedom of action on the international scene. But the same aestheticized, uncompromising approach to politics threatens the very democratic process which the discourse claims to protect; this occurs in the form of authoritarian conduct, including throwing suspicion on and intimidating critical voices in public debate, and in the shape of exponentially grow- 
ing surveillance activities that threaten to undermine civil liberties. The politico-cultural formation of experience which is caused by this polarising aestheticization of politics internally in democratic societies is thus characterised by a narrowing of the horizon of reflection and a disempowered orientation towards conformity with the politicians in power.

\section{Artistic interventions into politics}

Art has the potential to offer quite a different type of aesthetic intervention into politics. Whereas the two types of aestheticization mentioned above both intervene on the conflict level (A) of the political process, where they affect the relations of power and as an indirect effect influence the politico-cultural formation of experience, the interventions of art are not orientated towards power politics. When art intervenes into politics, it happens via the cultural public sphere, where art by way of its specific formal and thematic tools creates 'odd' new insights and ways of experiencing, and on this basis offers its own, specific space of reflection as a mirror to other discursive fields, including the political.

Intervening art thus addresses the critically reasoning citizen and aims, on the premises of aesthetic discourse, at establishing an enlightened dialogue on the common concerns of society. Its area of operation is the general public debate, in which the mediation between the levels of conflict and consensus of the political process takes place - in other words, in relation to the above model, art intervenes into the experience-processing interplay between the levels. On the basis of the indeterminately challenging discourse of aesthetic practice, art therefore contributes to opening up established formations of meaning, to the renewed processing of the conflictual experience of society, and to the further development and transformation of politico-cultural consensus - but without relating directly to the struggles of power and distribution of resources on the level of conflict (A).

But not all art which defines itself as political lives up to these ideal principles - just as not all art which actually meets these standards defines itself as political. To exemplify the former, one could mention the multiplicity of political, artistic activities in the 1970s, where the dominant, determining effort to 'take the correct stand in the class struggle' often made impossible a formation of meaning on the basis of the opening, non-determining, aesthetic discourse. On the contrary, the intervention was supposed to be determining and goal orientated in order to change the balance of power and the distribution of resources on the level of conflict (A), and in reality the intervention was thereby defining itself out 
of the field of art and into the field of political discourse - where it was usually unable to contribute with anything of interest either; that is to say, the message could be adequately expressed within political discourse.

As a counter-image to this type of artistic intervention we could mention the Danish political theatre group Solvognen and their "Army of Santa Clauses", which in December 1974 performed happenings in Copenhagen. The most spectacular event took place in the Magasin du Nord department store, where the Santas took commodities from the shelves and freely gave them away to by-standing children and adults, with the merry Christmas message of warmheartedness and generosity as their motto. Subsequently, the public experienced the realities of capitalism, as security guards and shop assistants tore the presents out of people's hands in the name of private property, and as Santa Claus - the children's friend and incarnation of jollity, harmonious fellow-feeling, and Christmas cosiness - was brutally hand-cuffed and taken away by the police under charges of disturbing the peace and violating private property. This scenery effectively played several established, emotionally anchored formations of meaning against each other, but without closing this freshly opened space of reflection by way of a determining moral. Here, the public was invited to engage in a genuine process of aesthetic experience - in a conflictual interplay between the aesthetic and political discourse in which their respective autonomies were maintained - and at the same time, basic, potentially violent social power relations were exposed under the Christmas decorations.

Another example of art that fulfils the ideal principles of successful aesthetic intervention into politics is Jimi Hendrix's instrumental reinterpretation of "Star Sprangled Banner" at the Woodstock Festival in 1969. The institutionalised aesthetic patterns of expectation related to national hymns are centred around harmony, community, and concordance. But against the backdrop of the Vietnam War, Hendrix undermines the national hymn's assertion of harmony by including long, disharmonious improvised passages with highly distorted guitar imitations of bombers, detonating grenades, and cries of pain in his musical expression. In this interpretation, the official aesthetic self-presentation of the United States bears testimony to anything but the proclaimed mission for peace and democracy, and the martial aggressiveness with which the expression of the national hymn is charged thus also points inward into American society, to a national community dangerously divided against itself. Apart from delivering a hitherto unsurpassed piece of basic research into the expressive potential of the electric guitar, Hendrix takes a well-defined genre as his starting point and dissolves it from within, thereby opening new possibilities of meaning. 
A contemporary match in the field of literature can e.g. be found in the poem På os skal land bygges by Ursula Andkjær Olsen (Olsen 2005). Here, scattered bits and pieces from the Danish cultual heritage serve as material for improvisation: the medieval code of law, Jyske Lov, the national anthems (Denmark has two of them), and the national song treasure in general are being dissolved and composed again in new constellations. But the national idyll is further interspersed with elements from the sphere of realpolitik, which complicates the picture. Realpolitik's social and ethnic mechanisms of marginalisation that are in the political discourse legitimised by stolid, technocratic calculations, are in this intervention confronted with emotionally charged formations of meaning originating from the historically and culturally rooted imagination of a harmonious, national community. The confrontation is sharp, but remains undetermined and thus embarks the reader on a critically reflecting seeking process between the discursive poles.

Common to these three examples of aesthetic interventions into politics is their maintenance of the autonomy of discourses and the fact that their critical approach is not abstract utopian, but immanent: their indeterminate challenging and opening of the formations of meaning of politics refer to normative potentials which have already been developed and anchored in the politico-cultural formation of experience on the level of consensus (B), and to which politics therefore in principle should be committed. The inconsistencies demonstrated by the aesthetic interventions thus represent real dilemmas for political practice, and in an unspecific way they therefore challenge political life to reflect on possible alternative forms of practice.

As has been shown, the interplay between the aesthetic and the political occurs in quite diverse shapes in late modernity, and these shapes imply correspondingly diverse perspectives for the development of culture and society. A critical point is the question of whether discursive autonomy is being maintained in the interplay or, instead, one discourse colonises the other, resulting in the reduction of the potential for reflection and formation of meaning of the colonised discourse. As to aesthetic discourse, another main question is whether it intervenes into politics in monologic forms that deny conflict or its approach takes the shape of a dialogic, challenging appeal in the service of enlightened conversation in society, in which case it would be able to contribute to qualifying political discourse. 


\section{Notes}

1. 'Bildung' is a key concept in German philosophy. It conceptualises human growth processes which integrate the development of individuals' sensory, emotional and intellectual potentials and make them capable of reflecting on themselves in terms of their embeddedness in and obligation toward the social and cultural context

2. The basic line of thinking behind the model was developed in my habilitation (Nielsen 1991) as a result of a major comparative analysis of the politico-cultural interplay between new social movements and political establishment in Denmark and West Germany in the 1960s, 70 and 8os. It was later (Nielsen 1993) elaborated and presented as a generalised thesis on the basic relations of the political process in modern, democratic societies.

\section{References}

Bisgaard, Ulrik and Carsten Friberg (ed.). 2006. Det cestetiskes aktualitet. Copenhagen: Multivers.

Bubner, Rüdiger. 1989. Ästhetische Erfahrung. Frankfurt am Main: Suhrkamp.

Duelund, Peter. 1995. Den danske kulturmodel. Århus: Klim.

Giddens, Anthony. 1991. Modernity and Self-Identity. Stanford: Stanford University Press.

Habermas, Jürgen. 1981. Theorie des kommunikativen Handelns, Vols. 1-2. Frankfurt am Main: Suhrkamp.

Huntington, Samuel P. 1998. The Clash of Civilizations and the Remaking of World Order. London: Touchstone Books.

Kant, Immanuel. 1963 (1790). Kritik der Urteilskraft. Stuttgart: Reclam

Knodt, Reinhard. 1994. Ästhetische Korrespondenzen. Stuttgart: Reclam.

Langsted, Jørn. 1990. Strategies. Århus: Aarhus University Press.

Nielsen, Henrik Kaare. 1991. Demokrati i bevagelse. Studier i politisk kultur og nye sociale bevoegelser i Danmark og Vesttyskland. Århus: Aarhus University Press.

Nielsen, Henrik Kaare, 1993. Kultur og modernitet. Århus: Aarhus University Press.

Nielsen Henrik Kaare, 1996. Astetik, kultur og politik. Århus: Aarhus University Press.

Nielsen, Henrik Kaare, 2001. Kritisk teori og samtidsanalyse. Århus: Aarhus University Press.

Nielsen, Henrik Kaare. 2005. "Totalizing Aesthetics? Aesthetic Theory and the Aestheticization of Everyday Life", The Nordic Journal of Aesthetics, no. 32.

Olsen, Ursula Andkjær. 2005, Egteskabet mellem vejen og udvejen. København: Gyldendal. 
Discursive Interventions

Prokop, Dieter. 2005: Der kulturindustrielle Machtkomplex. Köln: Herbert von Halem Verlag.

Schulze, Detlef Georgia m.fl. 2006. Politisierung und Ent-Politisierung als performative Praxis. Münster: Westfälisches Dampfboot.

Seel, Martin. 2003. Ästhetik des Erscheinens. Frankfurt am Main: Suhrkamp. Welsch, Wolfgang. 1990. Ästhetisches Denken. Stuttgart: Reclam

Ziehe, Thomas. 2004. Øer af intensitet i et hav af rutine. Copenhagen: Politisk Revy. 